
кокачественное развитие

УДК 330.341

DOI: $10.18101 / 2304-4446-2019-4-49-56$

\title{
ЭКОНОМИКА АВТОНОМНОГО РАЙОНА ВНУТРЕННЯЯ МОНГОЛИЯ: КУРС НА ВЫСОКОКАЧЕСТВЕННОЕ РАЗВИТИЕ
}

\section{(C) Намжилова Виктория Очировна}

кандидат экономических наук, научный сотрудник, Бурятский научный центр СО РАН Россия, 670047, г. Улан-Удэ, ул. Сахьяновой, 8

E-mail: dayavika@yandex.ru

В статье рассматриваются особенности курса на высококачественное развитие экономики Китая, предусматривающего отход от «гонки за цифрами» и упор на качественные показатели развития экономики и благосостояния населения. Приоритетными задачами в реализации курса в Автономном районе Внутренняя Монголия (АРВМ) обозначены выравнивание экономической динамики, поиск новых драйверов роста, оптимизация отраслевой структуры. Автор приходит к выводу, что обозначенные еще в начале века ведущие отрасли, несмотря на их высокую ресурсоемкость, сохраняют высокий приоритет для АРВМ и в настоящее время. Курс на высококачественное развитие экономики АРВМ ставит задачи удлинения производственных цепочек, поощрения научно-исследовательских разработок на предприятиях, поиска инновационных путей апгрейда приоритетных отраслей (энергетики, углехимической промышленности, переработки сельскохозяйственной продукции и др.).

Ключевые слова: Автономный район Внутренняя Монголия; структура производства; драйверы роста; приоритетные отрасли; высококачественное развитие

\section{Для цитирования}

Намжилова В. О. Экономика Автономного района Внутренняя Монголия: курс на высококачественное развитие // Вестник Бурятского государственного университета. Экономика и менеджмент. 2019. № 4. С. 49-56.

Сорокалетие экономических реформ в Китае подвело страну к определенному рубежу: необходимости перехода от количественных к качественным показателям развития экономики и благосостояния населения. Хотя целесообразность «гонки за цифрами» подвергается критике и широко обсуждается в научных кругах Китая много лет, в официальной риторике властей этот вопрос получил широкое освещение лишь в последние годы. Как отметил в своем докладе Си Цзиньпин на XIX съезде Коммунистической партии Китая в октябре 2017 г., китайская экономика в настоящий момент находится на стадии преодоления труднейших барьеров в трансформации форм развития, оптимизации экономической структуры и замещении старых драйверов развития. Создание модернизированной экономической системы является насущным требованием и стратегической целью развития Китая. Необходимо ставить на первое место качество и отдавать приоритет эффективности ${ }^{1}$.

Провозглашение необходимости перехода от высоких темпов роста («гаосу цзэнчжан») к высокому качеству («гао чжилян») развития экономики стало ло-

1 Доклад Си Цзиньпина на 19-м съезде КПК // ИА Синьхуа: сайт. URL: http://russian.news.cn/2017-11/03/c_136726299.htm (дата обращения: 18.07.2019). 
гичным оформлением экономического курса Китая в условиях «новой нормальности», устойчивого замедления экономического роста. Высококачественное развитие стало основополагающим требованием для разработки экономической политики и макроэкономического регулирования. Поставлена задача обеспечить скоординированное развитие реального сектора экономики, научно-технических инноваций, современного финансового сектора и людских ресурсов. В целом курс на высококачественное развитие подкрепляется успешным внедрением инноваций, что подтверждается стремительным продвижением Китая в рейтинге «Глобальный инновационный индекс» (Global Innovation Index) с 37 места в 2008 г. до 17 места в 2018 г. $^{1}$

Безусловно, необходимость высококачественного развития с опорой на инновации является актуальным требованием для всего Китая, но ввиду его исключительно пестрого экономического ландшафта и особенностей пространственного развития важное значение приобретает региональный аспект обозначенного курса. Курс на высококачественное развитие детализируется в каждом регионе с учетом специфики его развития. Постановке проблем высококачественного развития экономики Автономного района Внутренняя Монголия (АРВМ) был посвящен июльский номер 2019 г. журнала «Бэйфан цзинзци» («Экономика Севера»), выступающего своего рода рупором экономической повестки региона. Приоритетными задачами в реализации курса в АРВМ обозначены выравнивание экономической динамики, поиск новых драйверов роста как ответ на затухающий инвестиционный бум, оптимизация отраслевой структуры и т. д.

1. Выравнивание экономического роста. Основной тренд последних лет в Китае - замедление темпов экономического роста - проявился в АРВМ более заметно. Если в период 2000-2012 гг. отмечался период ускоренного роста, когда ежегодные темпы прироста валового регионального продукта превышали общекитайские показатели как минимум на 2\% (а в период 2002-2009 гг. регион лидировал в Китае), то с 2013 г. наблюдается значительное ухудшение экономической динамики. Быстрое сокращение разрыва в 2013-2016 гг. сменилось уже отставанием от роста ВВП Китая в 2017 и 2018 гг. (рис. 1). Это привело к тому, что по размеру экономики АРВМ, постепенно поднимаясь в рейтинге китайских регионов с 24-го места в 2000 г. и удерживая 15-е место на протяжении 20082014 гг., в последние годы теряет позиции.

Таким образом, сверхвысокий рост экономики АРВМ в первое десятилетие нового века, обусловленный «низким стартом», благоприятными условиями региональной политики Пекина, был сменен жесткими условиями «новой нормальности». При росте ВВП Китая на $6,9 \%$ в 2017 г. и на 6,6\% в 2018 г. темпы роста экономики АРВМ составили всего $4 \%$ и $5,3 \%$ соответственно. Такой относительно вялый рост объясняется не только ухудшением общей макроэкономической ситуации в стране, ослаблением спроса на главный фактор производства региона - природные ресурсы, но и насыщением экономики АРВМ капиталом [1]. На сегодняшний день для обеспечения высококачественного развития ставится задача не гнаться за высокими показателями, избегать больших скачков в экономической динамике и контролировать рост в разумных пределах [2].

\footnotetext{
1 Всемирная организация интеллектуальной собственности: сайт. URL: https://www.wipo.int/publications/ru/details.jsp?id=4330 (дата обращения: 12.06.2019).
} 
B. О. Намжилова. Экономика Автономного района Внутренняя Монголия: курс на высококачественное развитие

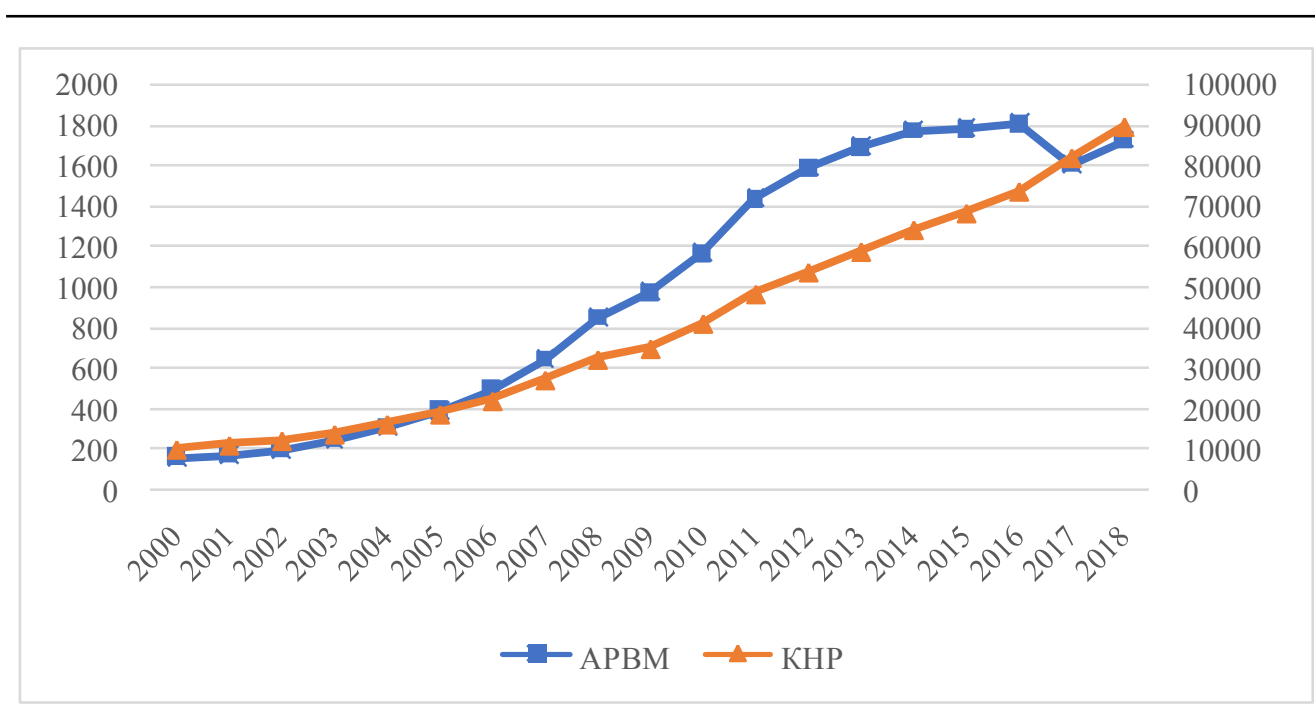

Рис. 1. Динамика ВРП АРВМ (левая шкала) и ВВП Китая (правая шкала), млрд юаней в текущих ценах, 2000-2018 гг.

Источник: сайт Государственного статистического управления KHP. URL: http://data.stats.gov.cn/

2. Смена драйверов роста. Известно, что с начала 2000-х гг. АРВМ переживает инвестиционный бум, в отдельные годы темпы роста капиталовложений были рекордно высокими по сравнению с другими регионами. Так, доля инвестиций в основной капитал в ВРП региона выросла с 27,5\% в 2000 г. до 76,5\% в 2010 г. Масштабные инвестиции направлялись на строительство современной сети коммуникаций, проекты по развитию инфраструктуры, освоение природных ресурсов, охрану окружающей среды. При этом основная часть капиталовложений пришлась на капитальное строительство и лишь пятая часть - на модернизацию и реконструкцию.

Такой приток капитала в АРВМ стал возможен в рамках реализации крупных региональных программ: сначала Программы освоения западных регионов, а позже - Стратегии возрождения старопромышленных баз Северо-Востока Китая. В целом меры государственной поддержки по упорядочению отраслевой структуры и строительству современных объектов инфраструктуры оказались своевременными и весьма эффективными. Однако в последние годы инвестиции демонстрируют незначительный рост, а по итогам 2018 г. и вовсе зафиксировано сокращение объема капиталовложений на $27,8 \%{ }^{1}$. Таким образом, инвестиции перестают быть главным двигателем экономики АРВМ. Движущей силой высококачественного развития должны стать инновации, включая не только применение научно-технических разработок в производстве товаров и услуг, но и внедрение инновационных управленческих практик [2].

3. Перестройка отраслевой структуры экономики. Локомотив экономического подъема АРВМ в 2000-е гг. - промышленность - в последние несколько лет быстро сбавляет темпы роста. Если ранее промышленность показывала вы-

\footnotetext{
${ }^{1}$ Статистическое управление APBM: сайт. URL: http://tj.nmg.gov.cn/ydcx/index.html (дата обращения: 11.07.2019).
} 
сокую положительную динамику с ростом в отдельные годы до 35\%, то начиная с 2014 г. этот показатель уходит из зоны двухзначного роста (рис. 2). В структурных изменениях все большую роль играет сфера услуг, или так называемый третичный сектор экономики. В целом совместное развитие передового производства и современной индустрии услуг признается основой высококачественного развития.

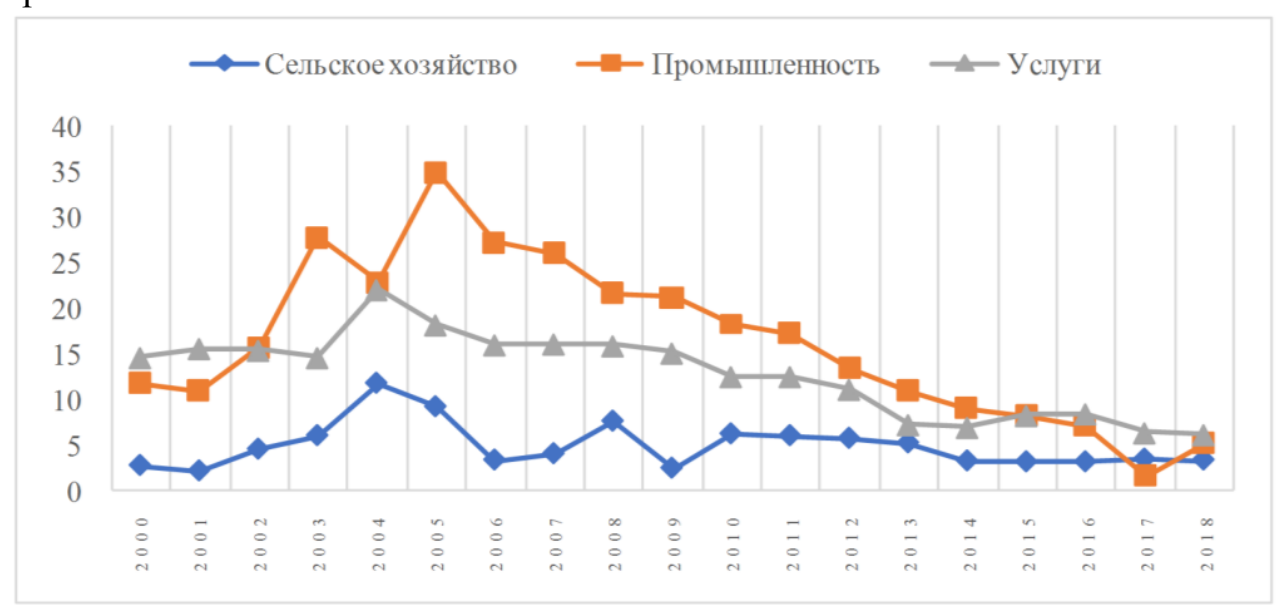

Рис. 2. Динамика темпов прироста ВРП АРВМ по трем секторам, \%, 2000-2018 гг. Источник: сайт Государственного статистического управления KHP. URL: http://data.stats.gov.cn/

Анализ отраслевой структуры экономики АРВМ за 2000-2018 гг. показывает, что пропорции трех секторов (сельское хозяйство, промышленность, услуги) менялись значительно и временами слабо коррелировали с общенациональными тенденциями. Если в период 2000-2010 гг. удельный вес промышленности и строительства в ВВП Китая держался в диапазоне 45-47\%, то в АРВМ этот показатель вырос с 37,8 до 54,5\% (табл. 1). К 2018 г. доля отраслей второго сектора снизилась до 40,7\% для Китая и до $39,4 \%$ в АРВМ. Доля сельского хозяйства за 2000-2018 гг. снизилась с 22,7 до 10,1\%, а доля сферы услуг выросла с 39,3 до $50,5 \%$.

Таблица 1

Валовый региональный продукт АРВМ по трем секторам в отдельные годы (млрд юаней)

\begin{tabular}{|c|c|c|c|c|c|}
\hline Годы & ВРП & $\begin{array}{c}\text { Сельское } \\
\text { хозяйство }\end{array}$ & Промышленность & Услуги & $\begin{array}{c}\text { ВРП на душу } \\
\text { населения } \\
\text { (тыс. юаней) }\end{array}$ \\
\hline 2000 & 153,9 & 35,0 & 58,2 & 60,5 & 6502 \\
\hline 2005 & 390,5 & 58,96 & 177,3 & 154,2 & 16331 \\
\hline 2010 & 1167,2 & 109,5 & 636,7 & 420,9 & 47347 \\
\hline 2015 & 1783,1 & 161,7 & 900,0 & 721,4 & 71101 \\
\hline 2018 & 1728,9 & 175,4 & 680,7 & 872,8 & 68302 \\
\hline
\end{tabular}

Источник: сайт Государственного статистического управления KHP. URL: http://data.stats.gov.cn/ (дата обращения: 10.07.2019). 
В. О. Намжилова. Экономика Автономного района Внутренняя Монголия: курс на высококачественное развитие

Скачкообразный рост промышленного производства АРВМ в первом десятилетии XXI в. стал возможен благодаря масштабному освоению природных ресурсов. Развитие получили все отрасли, связанные с углем: добыча, электрогенерация, металлургия, химическая промышленность. За 2000-2018 гг. годовое производство угля в АРВМ выросло с 72 до 925 млн т. (рост добычи в среднем на $15,2 \%$ в год). О значительной роли АРВМ в национальном производстве угля свидетельствует удельный вес региона в угледобыче - более $26 \%$. Кроме того, за 2000-2018 гг. производство электроэнергии в АРВМ увеличилось в одиннадцать раз: с 43,9 млрд до 482,8 млрд кВт/ч. Столь значительное наращивание генерации электроэнергии обусловлено двумя факторами. С одной стороны, это необходимость покрытия растущего потребления промышленности, по большей части энергоемких отраслей. С другой стороны, наращивание производства связано с необходимостью энергообеспечения регионов, испытывающих дефицит электроэнергии. На сегодняшний день за пределы автономного района направляется до одной трети выработанной электроэнергии. Можно утверждать, что за последние почти два десятка лет АРВМ сформировался как крупный энергетический форпост на севере Китая.

Энергетика наряду с другими пятью отраслями вошла в число приоритетных еще в годы реализации десятой пятилетки АРВМ (табл. 2). В настоящее время шесть приоритетных отраслей в совокупности обеспечивают более $95 \%$ добавленной стоимости в промышленности.

Таблица 2

Приоритетные отрасли промышленности в АРВМ

\begin{tabular}{|c|c|c|}
\hline № & $\begin{array}{l}\text { Наименование } \\
\text { отрасли }\end{array}$ & Основные виды продукции \\
\hline 1. & Энергетика & $\begin{array}{l}\text { Добыча каменного угля и природного газа, производство и распре- } \\
\text { деление электроэнергии }\end{array}$ \\
\hline 2. & Металлургия & Стальной прокат, сплавы цинка, алюминия и меди \\
\hline 3. & $\begin{array}{l}\text { Переработка c/x } \\
\text { продукции }\end{array}$ & $\begin{array}{l}\text { Молочная и мясная продукция, изделия из кашемира и овечьей } \\
\text { шерсти }\end{array}$ \\
\hline 4. & $\begin{array}{l}\text { Химическая про- } \\
\text { мышленность }\end{array}$ & Производство пластмасс, минеральных удобрений, сжижение угля \\
\hline 5. & Машиностроение & $\begin{array}{l}\text { Тяжелые грузовики, железнодорожный транспорт, инженерное } \\
\text { оборудование, ветряные установки, техника для геологоразведки }\end{array}$ \\
\hline 6. & $\begin{array}{l}\text { Высокие и новые } \\
\text { технологии }\end{array}$ & $\begin{array}{l}\text { Производство новейших материалов на основе редкоземельных } \\
\text { металлов, выпуск современных лекарственных препаратов, техно- } \\
\text { логии «облачных вычислений» }\end{array}$ \\
\hline
\end{tabular}

Примечательно, что данные отрасли сохраняют высокий приоритет для АРВМ и в настоящее время. Курс на высококачественное развитие не перечеркивает достижения прежних лет, пусть они получены экстенсивным путем. Развитие ресурсных отраслей позволило региону решить насущную проблему создания производственной базы, занять комфортную нишу по отдельным видам продукции (электрогенерация, углехимия, производство стальных рельс, концентраты редкоземельных металлов и др.). Признавая проблемы высокой ресурсоемкости и низкой добавленной стоимости выпускаемой продукции, АРВМ ставит за- 
дачи удлинения производственных цепочек, поощрения научноисследовательских разработок на предприятиях, поиска инновационных путей апгрейда приоритетных отраслей [3].

Так, в сфере энергетики АРВМ ориентируется на создание современной энергетической базы с высокой долей выработки чистой энергии. Наиболее перспективными направлениями развития «зеленой» энергетики в регионе является использование потенциала энергии ветра и солнца. С каждым годом возобновляемые источники энергии (ВИЭ) увеличивают свое присутствие в региональной структуре установленных мощностей. Так, на конец 2018 г. совокупная мощность энергоустановок ВИЭ достигла 40,5 млн кВт, что составляет третью часть генерирующих мощностей АРВМ. В регионе внедряются новейшие способы производства электроэнергии, появляются новые разработки в области ее распределения, хранения и потребления. Значительное влияние на развитие энергетики в ближайшем будущем будут оказывать такие тенденции, как цифровизация технологических процессов, широкое внедрение искусственного интеллекта и «умных» сетей.

Высокое качество развития планируется обеспечить и химическую промышленности, в частности путем создания образцовой базы современной углехимии. Проекты глубокой переработки угольного сырья, несмотря на долгий срок их окупаемости и относительно низкую рентабельность, являются перспективными ввиду нескольких причин. Во-первых, газификация и ожижение угля в местах добычи отвечают национальным задачам декарбонизации экономики крупных городов и позволяют поставлять в мегаполисы более «чистую» энергию. Вовторых, часть вывозимого угля (АРВМ поставляет в другие регионы Китая до $65 \%$ добытого угля) может быть направлена на переработку, при этом местные предприятия получают возможность выпускать продукцию с высокой добавленной стоимостью.

АРВМ ставит задачу создания базы производства и переработки экологически чистых продуктов питания. Переработке подвергается $62 \%$ всей сельскохозяйственной продукции, произведенной в регионе ${ }^{1}$. Если еще в начале $2000-$ - гг. отрасль опиралась только на два направления - молочную промышленность и переработку козьего пуха и шерсти, то на сегодняшний день деятельность отрасли получила значительную диверсификацию, включая направление мясопереработки. Согласно данным Департамента сельского хозяйства и животноводства АРВМ, общий объем производства мяса в 2018 г. в регионе составил 2,67 млн т, в т. ч.: свинины - 718 тыс. т, говядины - 614 тыс. т, баранины - 1,063 млн т, мяса птицы - 197 тыс. т $^{2}$.

\footnotetext{
${ }^{1} 2018$ нянь нунмуе чанье хэ нунсюй чаньпин цзягунъе лунтоу цие дэн фачжань гайкуан (Итоги деятельности ведущих предприятий производства и переработки сельскохозяйственной продукции в 2018 г.) [Электронный ресурс] // Департамент сельского хозяйства и животноводства APBM. URL: http://www.nmagri.gov.cn/zwq/ nmygk/农牧业产业化发展既兄/836623.shtml (дата обращения: 20.06.2019).

22018 нянь нунму е цзинзци фачжань цинкуан (Итоги развития сельского хозяйства и животноводства в 2018 г.) // Департамент сельского хозяйства и животноводства АРВМ [электронный pecypc] URL: http://www.nmagri.gov.cn/zwq/tjsj/831167.shtml (дата обращения: 20.06.2019).
} 
В. О. Намжилова. Экономика Автономного района Внутренняя Монголия: курс на высококачественное развитие

Поскольку АРВМ известен в Китае как производитель экологически чистых продуктов питания, перспективным становится продвижение местной продукции с использованием географической индикации, что позволит существенно повысить стоимость продукции. В числе узнаваемых торговых марок из Внутренней Монголии: «хулунбуирская баранина», «хорчинская говядина», «хинганский рис», «сунитская баранина», «учуаньский картофель» и много других продуктов с географической индикацией. Создание региональных брендов отвечает потребительским предпочтениям в части прослеживаемости товаров, соблюдения заявленных стандартов качества производства, экологических норм и т. д.

Развитие высокотехнологичных отраслей в АРВМ также опирается на ресурсы, прежде всего на исключительные запасы редкоземельных металлов. Кроме того, особой динамикой отличается сфера информационных технологий. Доступная электроэнергия, близость к столичному региону, а также климатические особенности сделали регион удобным местом размещения удаленных серверов «больших данных». По оценкам, данная отрасль к 2020 г. будет обеспечивать 100 млрд юаней валовой продукции региона с охватом около $10 \%$ китайского рынка [4].

Высококачественное развитие производства, модернизация отраслевой структуры экономики АРВМ нуждаются в технологических инновациях. Однако затраты на исследования и разработку отличаются не только малыми объемами, но и очень низким удельным весом в структуре BPП. Расходы на R\&D в APBM в 2017 г. составили 13,23 млрд юаней, что сопоставимо с $0,82 \%$ ВРП. Этот уровень расходов значительно отстает от общенационального показателя в $2,12 \%$ [5].

Помимо оптимизации отраслевой структуры важным для обеспечения высококачественного развития АРВМ является строительство экологической цивилизации, в частности создание «щита экологической безопасности» на севере Китая. Предпринимаемые меры включают не только природоохранные мероприятия, использование высоких экологических стандартов на производстве, функциональное экологическое зонирование территорий, но и внедрение экологических ценностей во все аспекты развития общества и воспитания людей.

Поскольку термин «высококачественное развитие» применительно к экономической динамике в Китае появился относительно недавно, определенные дискуссии вызывает возможность его измерения и оценки [2]. Открытым остается вопрос, какие индикаторы включать в систему оценки высококачественного развития и будут ли они универсальными для всех регионов.

\section{Литература}

1. Намжилова В.О. Экономическое развитие Автономного района Внутренняя Монголия в начале XXI века // Проблемы Дальнего Востока. 2019. № 3. С. 73-81.

2. Ван Юй. Нэймэнгу гао чжилян фачжаньдэ шэнькэ нэйхань хэ цзисюй цзецзюэдэ чжундянь вэньти [Глубокое содержание и актуальные проблемы высококачественного развития Внутренней Монголии] // Бэйфан цзинцзи. 2019. № 6. С. 28-30.

3. Чжао Хайдун. И синь фачжань линянь иньлин Нэймэнгу сяньдайхуа цзинцзи тиси цзяньшэ [Новая концепция развития для строительства современной экономической системы Внутренней Монголии] // Сайт Центра экономической информации APBM. URL: http://www.nmg.cei.gov.cn/information/nmg_jx41/msg1 1969209383.html (дата обращения: 20.06.2019).

4. Чжу Сяоцзюнь, Син Чжицан. Лунь Нэймэнгу цзинцзи гао чжилян фачжань «синь луцзы» дэ шидай тэчжэн юй луцзин [Дискуссии об особенностях «нового пути» высоко- 
качественного развития экономики Внутренней Монголии] // Бэйфан цзинцзи. 2019. № 6. C. $17-21$.

5. Хай Цинь. Чуаньсинь цюйдун чжичэн Нэймэнгу цзицзи гао чжилян фачжаньдэ тучу вэньти хэ чжолидянь [Инновации как драйвер высококачественного развития экономики Внутренней Монголии] // Бэйфан цзинцзи. 2019. № 6. С. 37-41.

\section{ECONOMY OF THE INNER MONGOLIA AUTONOMOUS REGION: QUALITY DEVELOPMENT COURSE}

Viktoria O. Namzhilova

Cand. Sci. (Econ.), Researcher,

Buryat Scientific Center SB RAS

8 Sakhyanovoy St., Ulan-Ude 670047, Russia

E-mail: dayavika@yandex.ru

The article discusses the course towards quality development of the Chinese economy, which provides departure from the "race for numbers" and emphasis on the quality indicators of economic development and welfare of the population. The alignment of economic dynamics, search for new growth drivers, and optimization of the production structure are the priority tasks in implementing this course in the Inner Mongolia Autonomous Region. We have come to the conclusion that the leading industries defined at the beginning of the $21^{\text {st }}$ century, despite their high resource intensity remain priority for Inner Mongolia. The course towards quality economic development of the Inner Mongolia Autonomous Region sets the tasks for extension of production chains, encouragement of research at enterprises, search for innovative ways to upgrade priority sectors (energy, coal industry, agricultural processing, etc.).

Keywords: Inner Mongolia Autonomous Region; production structure; growth drivers; priority sectors; quality development. 